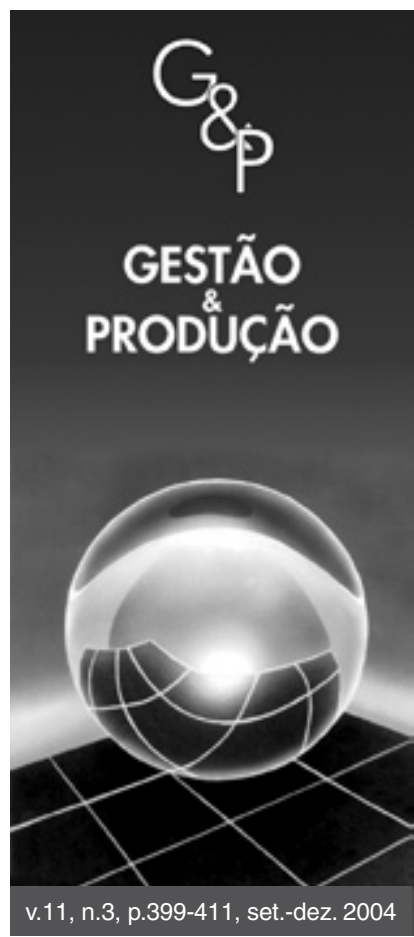

\title{
AUDITORIA E SISTEMA DE INFORMAÇÃO EM CANAIS DE INSUMOS DO AGRONEGÓCIO: PROPOSTA DE UMA FERRAMENTA DE PESQUISA
}

\author{
Lucas Teixeira \\ Marcos Fava Neves \\ Roberto Fava Scare
}

Universidade de São Paulo FEARP, Faculdade de Economia, Administração e Contabilidade de Ribeirão Preto, Av. dos Bandeirantes 3900, bloco C, sala 64, CEP 14040-900, Ribeirão Preto, SP, e-mail: lucasteix@ fearp.usp.br; mfaneves@usp.br; rfava@usp.br

Recebido em 01/7/2004

Aceito em 19/11/2004

Resumo

O crescimento apresentado nos últimos anos pela agroindústria traz consigo maior demanda por insumos, pela exigência de produtores cada vez mais profissionalizados. Assim, o entendimento dos canais de distribuição do setor, em um ambiente de crescente competitividade, exige que as empresas busquem instrumentos de avaliação periódica nestes estabelecimentos, principalmente no varejo, por ser o ponto de contato entre fabricantes e consumidores.

O presente artigo aborda o tema auditoria de varejo, tendo em vista identificar sua aplicabilidade neste tipo de canal de insumos agropecuários. Desta forma, o objetivo principal do trabalho é desenvolver um questionário que viabilize o uso desta ferramenta de monitoramento, no setor em questão. Para atingi-lo, foram realizadas pesquisas exploratórias em duas etapas sucessivas, sendo a primeira composta de revisão bibliográfica e a segunda de um estudo de campo. A aplicação do questionário em revendas de ração permitiu levantar os fatores de avaliação relevantes, além de sugestões e dificuldades de implantação do processo.

Por ser um assunto ainda pouco explorado no setor de insumos, o trabalho caracteriza-se como uma aplicação inicial da auditoria de varejo nesta área, visando, com isso, maximizar as informações recebidas pelos gerentes de marketing na cadeia de suprimentos do agronegócio.

Palavras-chave: auditoria de varejo, sistema de informação, canais de insumos agropecuários.

\section{Introdução}

Segundo a American Marketing Association (AMA), "canais de distribuição são conjuntos de organizações interdependentes envolvidas no processo de disponibilização de um produto ou serviço para uso ou consumo". Em um canal de distribuição, seus membros realizam diversas funções dentro do que os autores chamam de fluxos de marketing. Entre essas funções, Kotler (2000) destaca as seguintes:

- reunir informações sobre clientes, concorrentes e forças do ambiente de marketing;

- entrar em acordo sobre o preço e outras condições de transferência de posse;
- assumir riscos relacionados à operação do canal;

- fornecer condições para armazenagem;

- movimentação de produtos físicos; e

- pagamento das faturas dos compradores, entre outros.

Segundo Coughlan (2002), a grande interdependência dos membros do canal de marketing e o valor da especialização levam à necessidade de desenvolver esforços que considerem todos os elementos do projeto, visando assegurar a eficácia do gerenciamento deste setor da cadeia. Por serem entidades externas à empresa, situadas a jusante da cadeia, os canais de distribuição demandam certos cuidados aos gerentes de suprimentos, especialmente $o$ 
varejo, visto este ser o último negociante de um canal e o contato mais próximo entre fabricantes e consumidores.

A fim de monitorar a ação dos membros do varejo e evitar que eles desvirtuem a cooperação entre as partes e persigam unicamente seus próprios objetivos, surge a necessidade da empresa buscar ferramentas que avaliem o serviço delegado. Aspectos como o tamanho do lote a ser oferecido ao cliente, tempo de espera, conveniência espacial, variedade de produto e apoio de serviço devem ser analisados antes de ser firmada a parceria. Uma das principais ferramentas utilizadas para monitoria de canal é a auditoria de varejo e, no caso específico deste estudo, em revendas de insumos agropecuários.

Para Neves e Castro (2003), existem cerca de 8.000 revendas particulares atuando no ramo agropecuário do país, gerando 50.000 empregos diretos e utilizando 30.000 veículos, para chegar até o produtor. Em 2002, o faturamento dessas revendas foi de, aproximadamente, $\mathrm{R} \$ 3,6$ bilhões.

Com o crescimento do setor agroindustrial apresentado nos últimos anos, a demanda por insumos pelos produtores também é crescente. Conforme cita Etzel et al. (2001), pelo alto nível de renda resultante da venda de produtos agrícolas, atualmente, os fazendeiros são um grupo com poder de compra altamente atraente. $\mathrm{O}$ valor desse mercado e a concentração ocorrida nos últimos anos provocam o acirramento da competição no setor de insumos e, por conseqüência, nos canais de distribuição.

Assim, as revendas de insumos estão inseridas em um ambiente de grande competitividade, havendo, de um lado, forte disputa entre as indústrias pelo domínio destes estabelecimentos e, do outro lado, um cliente fortalecido e bastante exigente. Torna-se, portanto, indispensável às empresas produtoras de insumos, possuir ferramentas que apóiem a decisão de quais revendas farão parte da sua rede e como avaliá-las corretamente. Uma das formas mais utilizadas de monitoria de canais é, justamente, o sistema anteriormente citado, ou seja, a auditoria de varejo (em inglês, store audit).

Esse sistema é conhecido e amplamente utilizado no varejo, em supermercados principalmente. No Brasil, empresas multinacionais terceirizam essa atividade para diversas empresas ligadas à produção de alimentos. "Pioneira no desenvolvimento deste conceito, a ACNielsen, acompanha em todo o mundo a dinâmica dos mercados por meio de auditorias em lojas feitas por pesquisadores profissionais". Os dados obtidos pela empresa geram informações estratégicas e táticas para a indústria e para o varejo, possibilitando que os fabricantes acompanhem as movimentações do mercado, bem como a participação de suas marcas, e os varejistas avaliem a rentabilidade de marcas e categorias de produtos (ACNielsen, 2004). Diferentemente do setor de consumo, em que essa empresa atua fortemente, o setor de insumos agropecuários ainda não explora devidamente o uso desta ferramenta.

O crescimento do setor de insumos agropecuários, o acirramento da concorrência, a necessidade de maior integração dos agentes do canal de distribuição e a busca pelo setor de novas ferramentas de monitoria, em especial a avaliação de revendas por meio da auditoria de varejo, impulsionam a elaboração deste artigo.

Neste sentido, os objetivos deste trabalho podem ser assim descritos:

- conhecer os modelos de auditoria de varejo existentes;

- identificar a aplicabilidade desse sistema de monitoramento nas revendas de insumos agropecuários; $\mathrm{e}$

- desenvolver um sistema de informação que viabilize o uso da auditoria de varejo no setor de insumos agropecuários, pela proposição de uma sequiência de planejamento do processo.

A Figura 1 mostra, resumidamente, os canais de distribuição de insumos, identificando, dentro da amplitude do sistema, o foco da pesquisa (circulado em cinza), isto é, a criação de uma ferramenta de auditoria que possibilite maximizar o fluxo de informações do mercado para as indústrias do setor.

Visando o alcance da proposta, os seguintes objetivos específicos podem ser traçados:

- determinar a melhor forma de elaboração da auditoria de varejo: ferramenta, responsável, periodicidade, tipo e condução do processo; e

- levantar os fatores de avaliação nas revendas de insumos: composto de linha e produto, aspecto interno, promoção no ponto de venda, concessão de crédito, espaço de prateleira, preço e conhecimento técnico do vendedor sobre o produto, entre outros.

\section{Revisão bibliográfica}

\subsection{Sistema de informações de marketing}

Um sistema de informações de marketing (SIM) "é constituído de pessoas, equipamentos e procedimentos para coleta, classificação, análise, avaliação e distribuição de informações necessárias de maneira precisa e oportuna para os que tomam decisões de marketing" (Kotler, 2000). O papel do SIM é "avaliar as necessidades de informação da gerência, obter as informações necessárias e distribuí-las de maneira oportuna. As informações são desenvolvidas usando registros internos da empresa, atividades de inteligência e pesquisa de marketing e análise de suporte à decisão de marketing" (op cit). Isto está ilustrado na Figura 2. 
Voltando-se para este estudo, ressalta-se o sistema de inteligência de marketing e as pesquisas de marketing como fundamentais para a estruturação do sistema de auditoria. Segundo Kotler (2000), um sistema de inteligência de marketing é "um conjunto de procedimentos e fontes usado por administradores para obter informações diárias sobre eventos do ambiente de marketing". A coleta dessas informações pode ser feita por meio do relato de novos acontecimentos pelo pessoal de vendas, repasse de informações importantes por distribuidores, revendedores e outros intermediários motivados pela empresa, compra de informações de fornecedores externos como a ACNielsen, entre outros. Por outro lado, esse autor explica que a pesquisa de marketing corresponde à elaboração, coleta, análise e edição de relatórios sistemáticos de dados e descobertas relevantes sobre uma situação específica de marketing enfrentada pela empresa.

\subsection{Canais de distribuição de marketing}

Canais de Distribuição são “as redes de organizações que movimentam um produto desde o produtor até o seu mercado pretendido" (Czincota, 2001). Um canal de distribuição típico compreenderia os seguintes membros do canal: o fabricante que produz o produto e o vende a um atacadista, o atacadista que o revende a um varejista e este que vende o produto ao consumidor final. O esforço do canal depende do desempenho de vários fluxos de marketing, como ilustra a Figura 3.

Em geral, os fluxos devem ser compartilhados somente por aqueles membros de canal que podem agregar valor ou reduzir custos ao assumi-los. Entretanto, a especialização aumenta a interdependência nos canais, criando a necessidade de coordenação e cooperação em operações de canal (Coughlan, 2002).

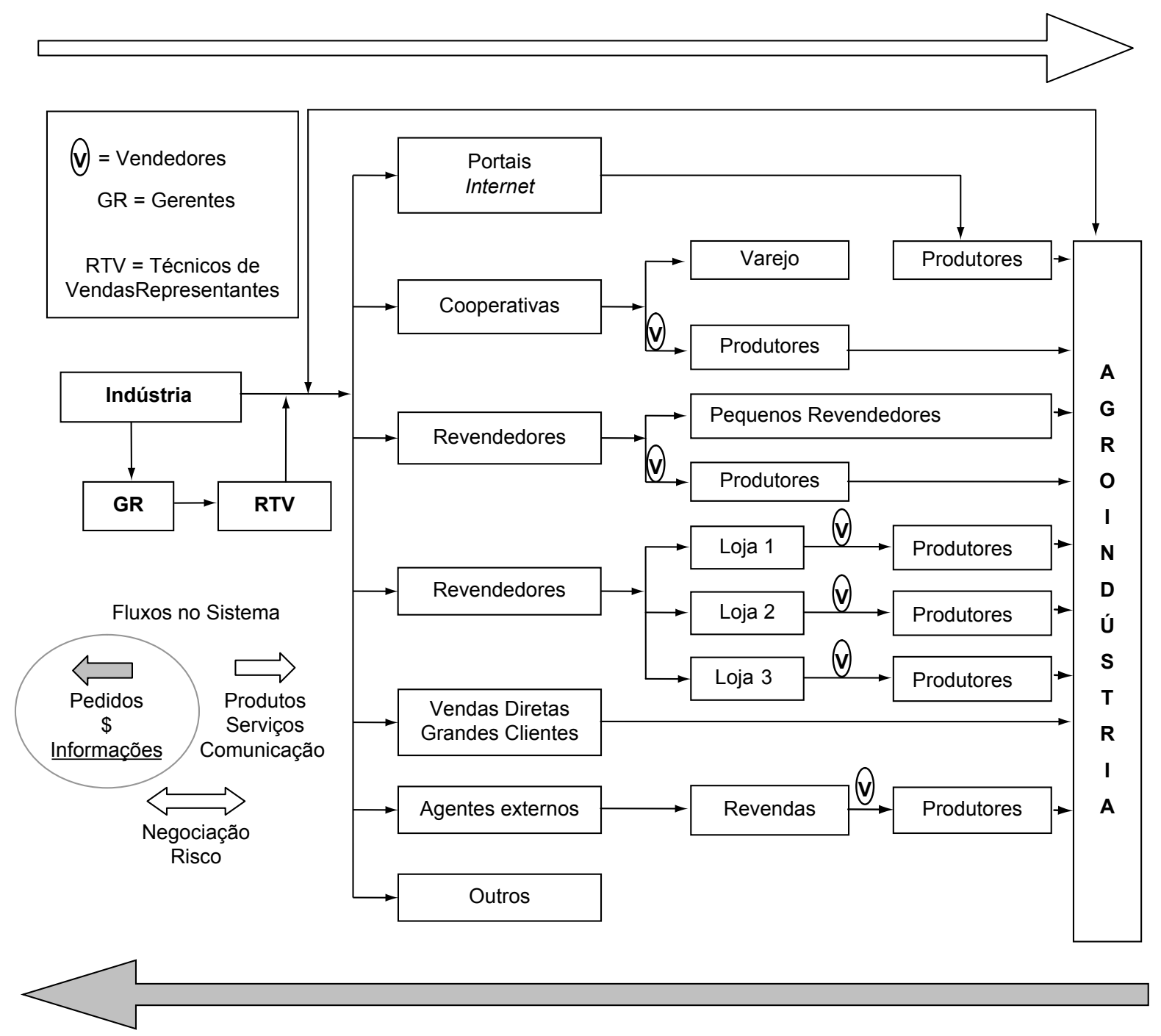

Figura 1. Rede de distribuição de insumos.

Fonte: Adaptado pelos autores a partir de Neves e Castro (2003). 


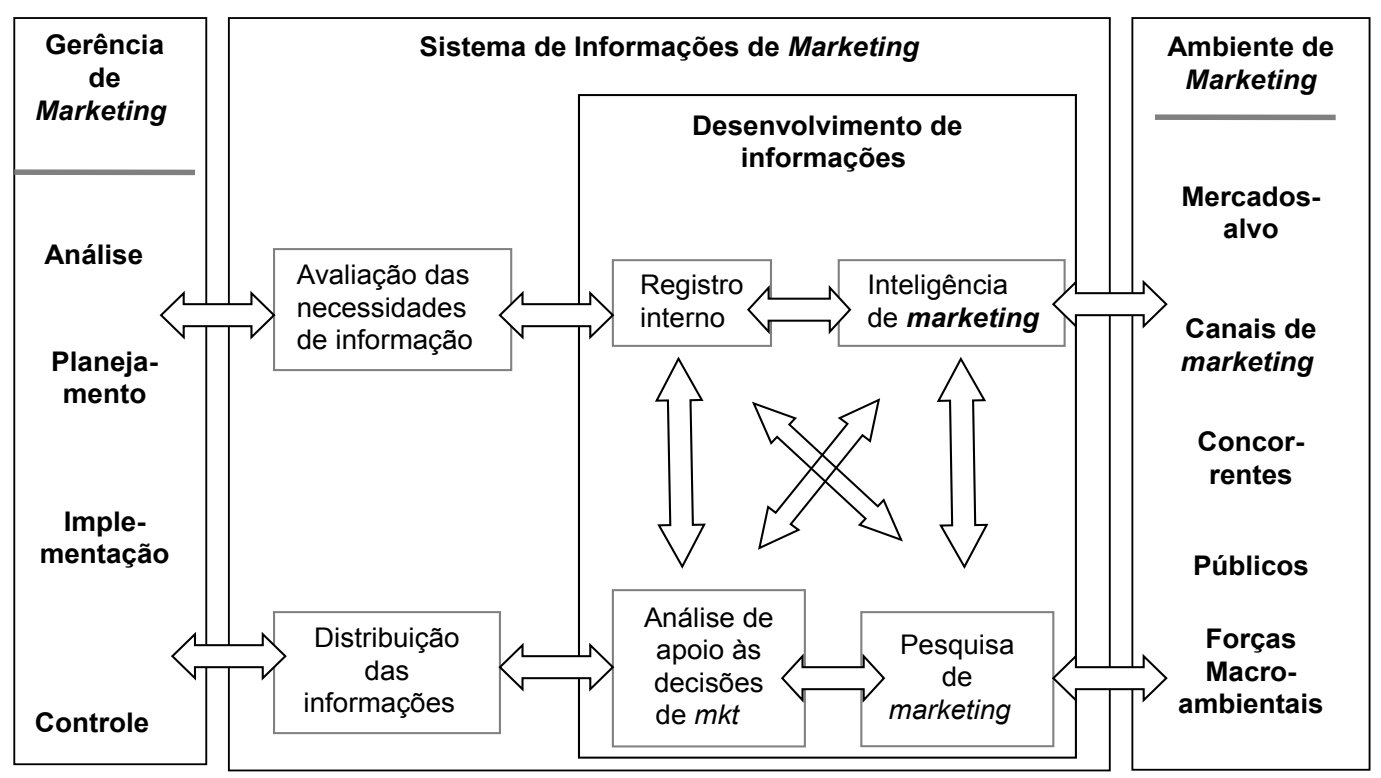

Figura 2. Sistema de informações de marketing. Fonte: Kotler (2000).

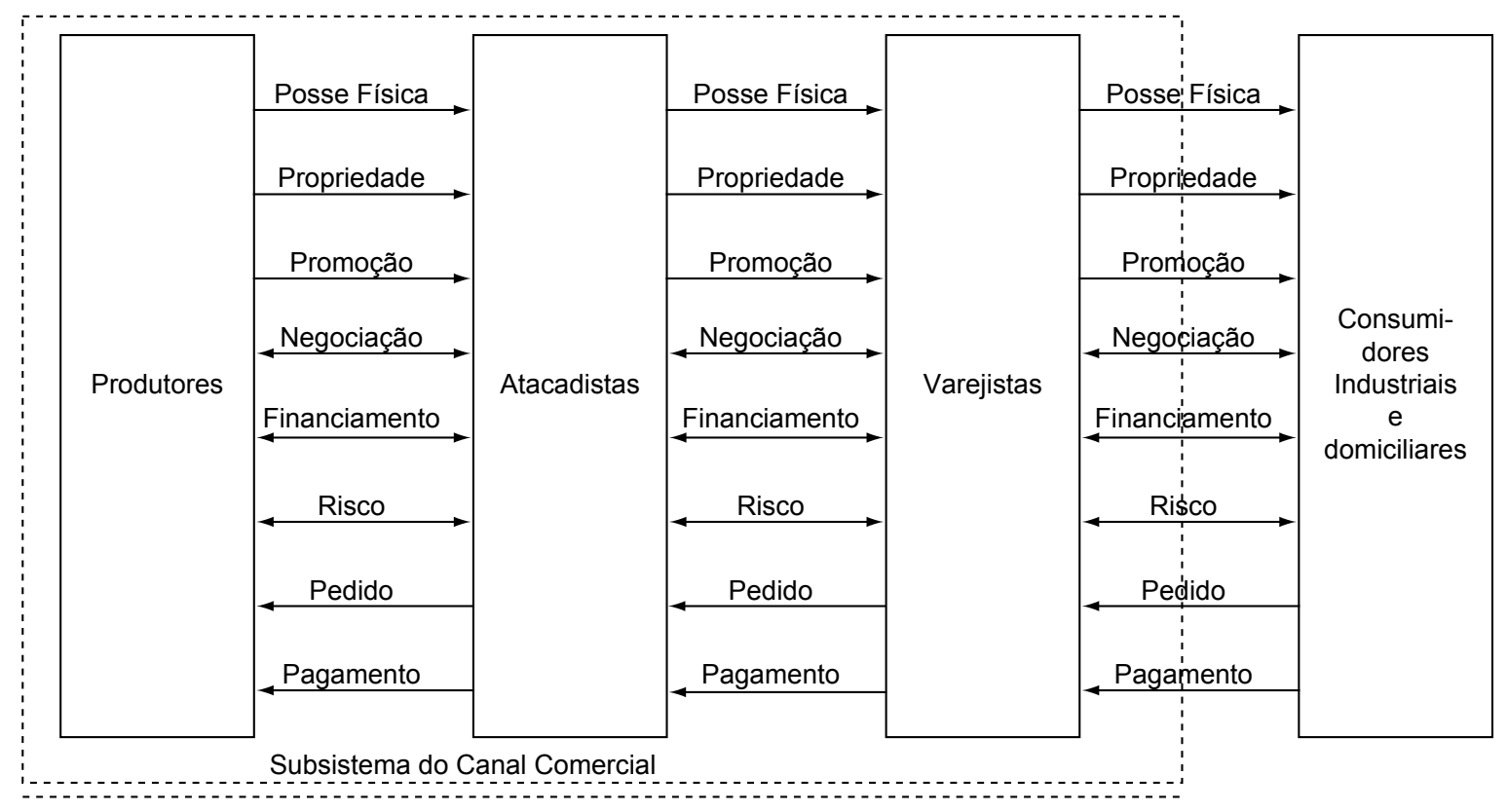

Figura 3. Fluxos de marketing no canal.

Fonte: Coughlan (2002).

\subsubsection{O Papel do varejo}

Segundo a AMA, varejo é "a unidade de negócio que compra mercadorias de fabricantes, atacadistas e outros distribuidores e vende diretamente a consumidores finais e eventualmente aos outros consumidores" (Las Casas, 1994).

Um varejista é o último negociante de um canal de distribuição que liga fabricantes a consumidores. Os varejistas encarregam-se de negociar e efetuar funções que aumentem o valor dos produtos e serviços vendidos aos consumidores. Essas funções são: fornecer uma variedade de produtos, dividir lotes grandes em pequenas quantidades, fornecer serviços (crédito, teste de mercadoria, informações adicionais sobre produtos, entre outros) e manter estoque (Levy e Weitz, 2000).

\subsection{A auditoria de varejo}

Conforme Levy e Weitz (2000) sugerem, a auditoria de situação é uma análise de oportunidades e de ameaças do ambiente de varejo e dos pontos fortes e fracos de um 
negócio de varejo em relação a seus concorrentes. Focando-se na análise de pontos fortes e fracos, o varejista deve considerar as seguintes variáveis:

- capacidade de gerenciamento (experiência, capacidades e comprometimento dos gerentes para com a empresa);

- recursos financeiros (fluxo de caixa e habilidade para aumentar ou criar débito ou financiar patrimônio líquido);

- operações (estrutura de custo de despesas gerais, qualidade dos sistemas operacionais, capacidade de distribuição e sistemas de informações gerenciais, prevenção de perdas e controle de estoque);

- capacidades comerciais (habilidade dos compradores, relacionamento com fornecedores, capacidade de criação de marcas próprias, de promoção e de publicidade);

- capacidade de gerenciamento de loja (comprometimento e qualidade técnica dos vendedores); e

- fidelidade do cliente e localização.

Por outro lado, a auditoria de varejo corresponde ao "monitoramento contínuo de uma amostra representativa de varejos". Consiste em "buscar, por meio de um serviço de pesquisa ou de análise especial, informações precisas relativas ao comportamento do produto no varejo, verificando-se as vendas diretamente nos pontos-de-venda, assim como os estoques e os preços ao consumidor" (ABM\&N, 2003).

A auditoria é uma ferramenta de avaliação vital para a estratégia de varejo. Ela consiste "no exame e avaliação sistemática dos esforços totais de varejo, com o propósito de estudar as ações presentes dos varejistas, analisar a performance do estabelecimento e fazer recomendações para futuras ações" (Berman e Evans, 1998). Uma boa auditoria inclui vários elementos importantes: condução regular do processo, análise sistemática de dados, perspectiva aberta a novas idéias durante sua aplicação, decisores engajados a tecer recomendações a partir do relatório de auditoria, entre outros.

\subsection{0 setor de insumos agropecuários}

Apesar da intensa competição no setor, a comercialização de insumos agrícolas no Brasil é uma atividade próspera. Com cerca de 5.500 colhedoras e 33.000 tratores vendidos, o setor de máquinas agrícolas faturou mais de R \$ 3,5 bilhões em 2002. As vendas de fertilizantes somaram $\mathrm{R} \$ 10$ bilhões, por meio da comercialização de 19 milhões de toneladas. Os 17 milhões de toneladas de calcário agrícola aplicados ao solo, foram responsáveis pela movimentação de R $\$ 289$ milhões nesse setor. Também foi relevante a participação dos defensivos agrícolas (inseticidas, fungicidas, herbicidas, acaricidas e outros) nas vendas de insumos em 2002, pois só este setor faturou, aproximadamente, R \$ 5,5 bilhões. As vendas de sementes, com destaque para as culturas de soja e milho, atingiram R $\$ 2$ bilhões (Neves e Castro, 2003).

Além da concentração da propriedade das terras, maior profissionalização e especialização dos produtores, pela crescente complexidade gerencial das culturas, verificase que o produtor prefere ter acesso à tecnologia de forma direta como, por exemplo, em dias de campo. Ainda existem barreiras no fornecimento de dados do produtor rural e abertura de seus negócios para outras empresas, por exemplo, pelo fato de perder o controle dos negócios e, conseqüentemente, sua capacidade de negociar melhor. O produtor quer soluções completas (aplicação, fertilizantes, defensivos, comercialização, entre outros), porém ainda não encontra muitas empresas de sua segurança (confiança), para honrar os compromissos destas soluções e que se aproximem de fato de seu negócio principal (op cit).

\section{Método de pesquisa}

A fim de atingir os objetivos propostos, duas pesquisas exploratórias complementares entre si foram elaboradas sucessivamente (Malhotra, 2001).

Primeiro realizou-se uma revisão bibliográfica sobre sistemas de informação de marketing, canais de distribuição/varejo e auditoria de varejo, seguida de um levantamento em base de dados secundários, para conhecimento do tamanho e importância do setor de insumos agropecuários. Esses estudos, além de servirem como base ao seqüenciamento de etapas para planejamento do processo de auditoria de varejo, proporcionaram o conhecimento necessário ao início da segunda pesquisa.

Assim sendo, a etapa seguinte, também exploratória, constituiu-se da elaboração de um estudo de campo pela aplicação de questionário (ver anexo) em uma amostra, incluindo revendas de insumos agropecuários do ramo de alimentação animal na cidade de Ribeirão Preto (SP), de abril a junho de 2003, totalizando 22 estabelecimentos visitados.

\section{Resultados da pesquisa de campo: seqüência proposta para planejamento de auditoria de varejo no setor de insu- mos agropecuários}

Durante os três meses de estudo na parte empírica do trabalho, vinte e duas revendas de rações foram visitadas, gerando conhecimento suficiente para a proposta de uma ferramenta de pesquisa e seqüenciamento de sua construção.

Segundo Kotler (2000), dois dos quatro componentes de 
um moderno sistema de informações de marketing são: a pesquisa de marketing e a inteligência de marketing. $\mathrm{O}$ primeiro relaciona-se diretamente com a auditoria de varejo, no que tange às etapas de planejamento e construção do processo em si, ao passo que o outro aborda a frequiência na coleta de informações como ponto comum.

Embora não seja ainda muito difundida no setor de insumos agropecuários, Berman e Evans (1998) afirmam que a auditoria de varejo apresenta importância vital na estratégia de uma empresa, sendo necessárias seis etapas para seu planejamento:

(1) determinar quem fará a auditoria;

(2) determinar quando e com que freqüência a auditoria será efetuada;

(3) determinar o tipo de auditoria;

(4) desenvolver as ferramentas de auditoria;

(5) conduzir a auditoria; e

(6) reportá-la à gerência.

Associando os objetivos propostos com os passos citados pelos autores, nota-se claramente a necessidade de direcionamento do foco à quarta etapa listada, tornandose viável a seguinte divisão de atividades: determinação do responsável, periodicidade de visitas, tipo e condução da auditoria; e desenvolvimento da ferramenta de auditoria de varejo.

\subsection{Determinação do responsável, perio- dicidade de visitas, tipo e condução da auditoria}

A auditoria de varejo envolve, antes de qualquer coisa, a escolha única ou combinada dos responsáveis pelo processo: auditor interno especializado, auditor externo ou gerente de departamento.

Cada um deles apresenta vantagens e desvantagens para a empresa. No caso dos auditores, ambos são bastante onerosos para a empresa, porém, enquanto o primeiro já possui conhecimento aprofundado da organização, o segundo apresenta maior independência e liberdade de ação. Cabe à empresa decidir o fator crítico, ou seja, priorizar a economia de tempo com a familiarização organizacional do indivíduo, ou o compartilhamento de informações de maior veracidade e desprendimento. Gerentes de departamento conhecem melhor o dia-a-dia operacional da empresa, além de não demandarem grandes custos adicionais, em contrapartida, isso pode comprometer a qualidade de seu trabalho original.

Embora alguns varejistas exijam menor periodicidade, uma auditoria de varejo costuma ser conduzida anualmente (ano contábil ou fiscal). A empresa que colaborou com o artigo, cedendo a lista das revendas que foram vi- sitadas, não realiza esta atividade, porém se realizasse seria interessante a fixação de um período trimestral. Tanto ela como muitas organizações realizam reuniões gerais de diretoria dentro desta periodicidade, ocasião oportuna para a análise das informações geradas.

Existem dois tipos básicos de auditoria: horizontal (focada pelo artigo) e vertical. A primeira é considerada uma "auditoria estratégica de varejo" e envolve a análise da consistência do composto de estratégia básico de varejo (crédito, serviços, promoção no ponto de venda e disposição interna da loja) com a missão organizacional. A segunda volta-se para um processo mais especializado, focando apenas a análise aprofundada de uma das áreas deste composto.

Após a seleção do responsável, da periodicidade, do tipo e da ferramenta utilizada (item tratado a seguir), chega o momento da condução do processo de auditoria em si. As seguintes questões devem ser respondidas: Quanto tempo levará a visita? Os varejistas devem ser notificados antecipadamente? A auditoria deve ser disfarçada ou tratada abertamente? A auditoria deve ser feita quando o estabelecimento estiver aberto ou fechado?

Cabe ressaltar que a resposta a todas estas questões depende diretamente da cultura e dos objetivos organizacionais. No entanto, a aplicação das pesquisas nas revendas em questão revelou a necessidade de algo em torno de quinze a vinte minutos, para a aplicação do questionário durante horário comercial. Buscando evitar algum viés, não houve notificação antecipada, porém o propósito da visita à loja foi tratado abertamente com o varejista, visto que os tópicos não necessitavam de respostas estratégicas ou comprometedoras.

\subsection{Desenvolvimento da ferramenta de auditoria de varejo}

A principal etapa do desenvolvimento de um sistema de informação para auditoria de varejo no setor de insumos é a elaboração do questionário. Encontra-se em anexo a versão padronizada desta ferramenta. Apresentam-se agora os condicionantes, ou fatores de avaliação, levantados pelos questionários aplicados.

- Produtos oferecidos (composto de produto e de linha):

Buscando determinar a variedade e o sortimento de uma categoria, o varejista costuma considerar os seguintes fatores: lucratividade do conjunto de mercadorias, filosofia da corporação em relação ao sortimento, características físicas da loja e o grau com que as categorias de mercadorias se complementam (Levy e Weitz, 2000).

Descobrir qual é o portfólio de produtos de cada revenda, bem como a quantidade de marcas em cada linha é de suma importância para a organização. A partir desta informação, a empresa pode identificar possíveis oportunidades de investimento e ameaças da concorrência. 
- Caracterização da revenda:

Como o consumidor final da empresa corresponde à clientela dos estabelecimentos pesquisados, existe a necessidade desta avaliar alguns aspectos existentes no varejo. Características da revenda como o aspecto interno da loja, a promoção no ponto de venda, a concessão de crédito ao cliente e o espaço da prateleira foram analisados.

- Aspecto interno:

Quanto a esta característica, uma análise da disposição dos produtos na loja foi realizada. Para tal, surgiu a necessidade de verificar a adequação do local em que o produto estava, além do seu nível de exposição, ou seja, se a mercadoria estava ou não à vista do cliente.

Outro fator analisado foi a visibilidade do preço dos produtos. Cabe ressaltar que na maioria das lojas não existia uma precificação adequada das rações, já que, na maior parte delas, somente o preço da ração a granel era exposto.

A sofisticação da loja foi outro ponto observado. Esta análise mostrou-se um fator bastante subjetivo, visto que era levada em conta a "primeira impressão" que o aplicador da pesquisa tinha a respeito da loja. A visualização geral do estabelecimento, juntamente com a experiência adquirida na aplicação do questionário em diversos locais, dava ao aplicador uma base de comparação para efetuar análises posteriores.

Para projetar uma boa disposição de loja, dois pontos a serem observados, segundo Levy e Weitz (2000), são a facilitação do tráfego no estabelecimento e o equilíbrio entre o espaço para o cliente e alocação de prateleiras, mercadorias e promoção no ponto de venda. Sendo assim, dois pontos analisados também importantes foram: o espaço existente para que o consumidor possa locomover-se e melhor encontrar os produtos de que necessita, e a poluição visual, isto é, a quantidade de objetos que surgem no campo de visão do consumidor. $\mathrm{O}$ excesso desta pode, além de prejudicar seu conforto, atrapalhar sua procura de consumo.

Visto que as revendas de rações apresentavam a possibilidade de compra a granel, além da existência de animais engaiolados, o surgimento de um ambiente com limpeza insatisfatória, cheiro forte e poluição auditiva (ruídos), consideravelmente excessiva, acabava tornando-se presente no ramo. Surgiu, então, a necessidade de avaliação destes tópicos para que houvesse algum controle da atmosfera interna, oferecida ao consumidor;

- Promoção no ponto de venda:

Visando informar, persuadir ou lembrar o cliente, o varejista utiliza-se da promoção de varejo, cujo composto inclui: propaganda, relações públicas, promoção de vendas, venda pessoal e atmosfera da loja.

Obtendo uma visão adequada do material promocional que existe nas revendas e, logo, dos investimentos em propaganda da concorrência, a empresa pode, não somente ter idéia a respeito do visual de marca que cada loja apresenta, mas também conseguir novas idéias de investimento em publicidade.

Uma averiguação atenciosa do local permitiu que o aplicador descobrisse oportunidades de investimento publicitário, além da identificação de materiais promocionais diferentes e causadores de impacto;

- Concessão de crédito:

Tendo sempre em mente que o cliente do revendedor é o consumidor final do produto e, assim, o principal demandante dos cuidados da empresa, tornou-se necessário também a avaliação da concessão de crédito da loja.

Possuir uma grande quantidade de contas a receber, embora possa alavancar as vendas, custa caro para o varejista, já que cria custos de oportunidade que o impede de reinvestir o resultado das vendas em novas mercadorias, ou em qualquer outro tipo de investimento. Em contrapartida, as formas de pagamento bem como o prazo e os juros podem dificultar o processo de compra do indivíduo e provocar a desistência da marca;

- Espaço de prateleira:

Os planejadores de lojas, em conjunto com seus gerentes, normalmente começam alocando espaço conforme a produtividade de vendas. Os seguintes aspectos são considerados: rotatividade de estoque, lucratividade, exposição e localização da mercadoria.

A observação da quantidade de produtos de cada fabricante dentro da loja permite à empresa comprovar o domínio dos concorrentes nos estabelecimentos e, com isso, saber melhor para qual revenda focalizar seus esforços de distribuição, preço e propaganda.

- Indicadores quantitativos:

Dentre as variáveis incontroláveis, uma que tem maior impacto nas decisões de preços varejistas é, sem dúvida, o preço da concorrência (Las Casas, 1994).

Buscar números que gerem comparação entre os fabricantes é de grande importância para a empresa, visto que, assim, ela consegue quantificar determinados pontos (preço/kg, prazo, juros, \% de venda), que transmitam idéia de sua situação nas revendas frente à concorrência.

A variação percentual de preços, com relação aos 
concorrentes e a participação de mercado (em inglês, market share), puderam identificar traços do perfil estratégico dos principais concorrentes.

Questionar os balconistas a respeito dos atributos técnicos dos produtos, pode, além de dar uma visão sobre os pontos fortes e fracos de cada marca, gerar retorno do conhecimento transmitido pelos representantes da empresa à força de venda varejista.

\section{Limitantes ao estudo}

Algo existente, porém já esperado, visto que o tema pretendido envolve o desenvolvimento de uma ferramenta pouco explorada no setor em questão, é o aparecimento de dificuldades na aplicação da pesquisa.

Os problemas ocorridos associam-se a três pontos, fortemente presentes no desenvolvimento do trabalho: subjetividade e dificuldade na quantificação de fatores de avaliação, tempo de aplicação e despreparo dos balconistas.

Por tratar-se de aspectos consideravelmente subjetivos, os determinantes da caracterização interna da revenda trouxeram bastante dificuldade de classificação. O maior exemplo deles é o fator sofisticação. Para classificá-lo, levava-se em conta apenas a "primeira impressão" que o aplicador da pesquisa tinha a respeito da loja. A experiência adquirida na aplicação do questionário em diversos locais era o único ponto de referência a possibilitar base de comparação. Em conseqüência disso, as primeiras pesquisas aplicadas ficaram prejudicadas, visto que receberam notas sem uma noção precisa e fundamentada do aplicador a respeito dos estabelecimentos. O preparo prévio do funcionário pela empresa ou a utilização de representantes comerciais, como aplicadores de pesquisa, poderia ser a solução para reduzir a subjetividade destes critérios.

Ainda considerando problemas relacionados aos fatores de avaliação, é pertinente ressaltar a dificuldade encontrada na quantificação da participação de mercado e do espaço de prateleira na loja. Conforme já visto no questionário, esses aspectos foram quantificados mediante atribuição pessoal (do balconista e do aplicador) de valores percentuais aos fabricantes. Perdendo um pouco a precisão, porém melhorando a confiabilidade da medida, a utilização de uma classificação apenas ordinal poderia ser, a princípio, uma solução.
O segundo ponto gerador de dificuldade foi o tempo. É praticamente inexistente a exposição de preços (exceto promoções e mercadorias a granel) nas revendas de ração. Questionar o balconista, além de consumir muito tempo, tornava a visita desgastante para ambos os lados. Separar esta quantificação do restante da pesquisa e aplicá-la por telefone, ou por meio de outras visitas com este único propósito, resolveria esta questão.

O terceiro e último ponto limitante é o despreparo dos balconistas do setor analisado. O conhecimento técnico das rações deixava bastante a desejar, principalmente, quando era pedido que listassem as vantagens e desvantagens dos atributos de uma ração em relação à concorrente. Uma classificação apenas superficial, do tipo "melhor e pior empresa em qualidade e em preço", acabou sendo a saída encontrada.

\section{Considerações finais}

Como pode ser visto, a auditoria de varejo é algo ainda pouco explorado no mercado e, principalmente, no setor de insumos agropecuários. A sugestão de planejamento de um sistema de informação que viabilize a utilização desta importante atividade de avaliação e controle é, portanto, baseada especialmente na aplicação prática da pesquisa, visto que os problemas e limitações impostos pelo setor analisado exigem adaptações no desenvolvimento do processo. Apenas o uso desta ferramenta no cotidiano de trabalho das empresas de insumos é que propiciará os ajustes necessários para viabilizar sua utilização.

Assim, a elaboração deste artigo teve por objetivo construir um ponto de partida que busque, num futuro próximo, familiarizar a auditoria de varejo no setor de insumos e, com isso, maximizar as informações recebidas pelos gerentes de marketing da cadeia de suprimentos. Permitir que estes agentes estejam mais aptos a responder prontamente a ameaças e oportunidades de mercado, bem como a emergentes necessidades dos consumidores, é algo encarado como conseqüência final do trabalho.

Novos estudos nesta área poderão, ainda, não somente construir um método de avaliação de revendas de insumos, mas também buscar padronizar a estruturação das revendas pelas organizações, enquadrando disposição interna de loja, material promocional, aspecto interno e, até mesmo, serviço, dentro dos anseios das empresas.

\section{Referências Bibliográficas}

ABM\&N. Associação Brasileira de Marketing \& Negócios. Disponível em: <http://www.abmn.com.br/infomarketing/verbetes.asp>. Acesso em: 16 dez. 2003.

ACNIELSEN. Disponível em: <http://www.acnielsen.com. br>. Acesso em: 12 fev. 2004.
BERMAN, B.; EVANS, J. R. Retail Management. 7th. New Jersey: Prentice Hall, 1998. 768 p.

COUGHLAN, A. T. Canais de Marketing e Distribuição. 6. ed. Porto Alegre: Bookman, 2002. 461 p.

CZINKOTA, M. R. Marketing e as Melhores Práticas. 1. 
ed. Porto Alegre: Bookman, 2001. 559 p.

ETZEL, M. J.; WALKER, B. J.; STANTON, W. J. Marketing. 1 ed. São Paulo: Makron Books, 2001. 770 p.

KOTLER, P. Administração de Marketing. 10. ed. São Paulo: Prentice Hall, 2000. 764 p.

LAS CASAS, A. L. Marketing de Varejo. 3. ed. São Paulo: Atlas, 1994. 288 p.
LEVY, M.; WEITZ, B. A. Administração de Varejo. 1. ed. São Paulo: Atlas, 2000. 695 p.

MALHOTRA, N. K. Pesquisa de Marketing: uma orientação aplicada. 3. ed. Porto Alegre: Bookman, 2001. 719 p.

NEVES, M. F.; CASTRO, L. T. Marketing e Estratégia em Agronegócios e Alimentos. 1 ed. São Paulo: Atlas, 2003. 365 p.

\title{
AUDITING AND INFORMATION SYSTEMS IN AGRIBUSINESS INPUT CHANNELS: A PROPOSED RESEARCH TOOL
}

\begin{abstract}
The evolution of Brazil's agroindustry in recent years has led to a growing demand for input resources in response to the producers' increasingly professionalized profile. Therefore, a better understanding of this sector's distribution channels, which operate in an increasingly competitive environment, requires companies to seek tools for periodic evaluation, especially in the retail segment, the meeting point of manufacturers and consumers.

This article discusses retail auditing, identifying its applicability to the agribusiness marketing channel. The main goal of this study was to draw up a questionnaire for use as a tool to monitor the retail sector. A two-phase exploratory survey was carried out, the first consisting of a literature review and the second a field study. The application of the questionnaire at animal feed retail stores enabled us to detect relevant evaluation factors, receive suggestions and identify difficulties involved in the implementation of this process.

Since little research has been done in this specific sector, this study can be regarded as the initial application of retail store auditing in this field, aimed at maximizing information provided by marketing managers in the agribusiness supply chain.
\end{abstract}

Keywords: retail auditing, information system, agribusiness input channels. 


\section{ANEXO: Questionário - Auditoria de varejo para canais de insumos agropecuários}

- Revendedor:

Cidade:

Bairro:

Endereço:

CEP:

Tel:

- Proprietário/Vendedores

Listar o nome completo, primeiramente do proprietário, depois dos vendedores.

Destacar com um * a pessoa com que foi feito o contato.

- Produtos oferecidos

Listar as empresas que vendem as linhas selecionadas no questionário.

Identificar outras linhas vendidas na loja que não constem na lista pré-estabelecida.

\begin{tabular}{|c|c|}
\hline Linha & Empresas \\
\hline 1 & A ( ) B ( ) C ( ) D ( ) . \\
\hline 2 & \\
\hline 3 & \\
\hline 4 & \\
\hline$\ldots$ & \\
\hline
\end{tabular}

\begin{tabular}{|l|l|}
\hline Outras Linhas & \\
\hline & \\
\hline & \\
\hline & \\
\hline & \\
\hline & \\
\hline
\end{tabular}


- $\quad$ Caracterização da revenda

Conforme a percepção dentro da revenda, atribuir uma nota de 1 a 5 para as características listadas (Atenção: 1 - pior nota / 5 - melhor nota).

\section{- Aspecto interno}

\begin{tabular}{|c|c|c|c|c|c|c|}
\hline \multicolumn{7}{|l|}{ Disposição dos produtos } \\
\hline & 1 & 2 & 3 & 4 & 5 & \\
\hline - Adequação do local & & & & & & Adequação perfeita \\
\hline \multirow[t]{2}{*}{ - Nível de exposição } & 1 & 2 & 3 & 4 & 5 & \\
\hline & & & & & & Exposição perfeita \\
\hline
\end{tabular}

Visibilidade do preço

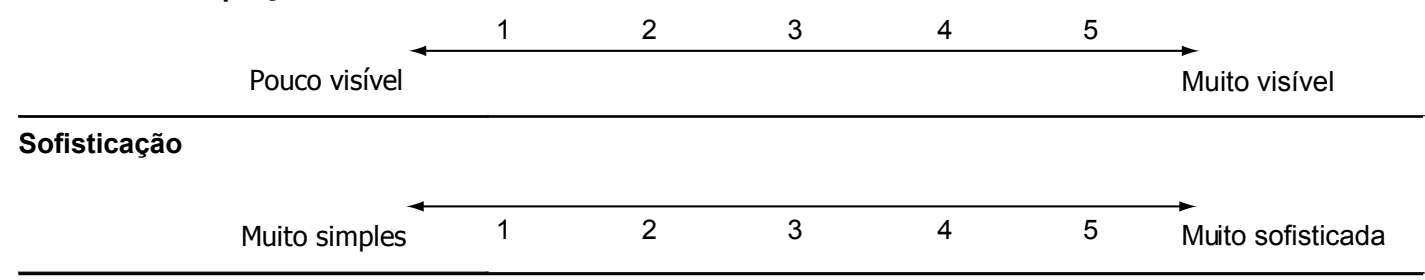

Espaço p/ o consumidor

Muito apertada $\begin{array}{lllllll} & 1 & 2 & 3 & 4 & 5 & \text { Muito espaçosa }\end{array}$

\begin{tabular}{lllllll}
\hline Poluição visual & \\
Muita poluição & & 1 & 2 & 3 & 4 & 5
\end{tabular}

\section{Limpeza}

\begin{tabular}{llllllll} 
Muito suja & & 1 & 2 & 3 & 4 & 5 & Muito limpa \\
\hline
\end{tabular}

\section{Cheiro}

Muito cheiro $\begin{array}{lllllll} & 1 & 2 & 3 & 4 & 5 & \text { Pouco cheiro }\end{array}$

\section{Poluição auditiva}

$\begin{array}{lllllll}\text { Muita poluição } & 1 & 2 & 3 & 4 & 5 & \text { Pouca poluição }\end{array}$

Descrever aspectos relevantes observados na atribuição das notas (Ex: tipo do cheiro, causa dos ruídos, justificativa de notas, etc).

Observações adicionais 


\section{- Layout}

Listar as empresas que possuem os materiais de propaganda selecionados no questionário.

Identificar outros materiais publicitários presentes na loja que não constem na lista pré-estabelecida.

Estar atento para apontar materiais de propaganda que apresentem certo destaque e oportunidades de investimento publicitário identificáveis na revenda.

\begin{tabular}{|l|l|l|}
\hline \multicolumn{1}{|c|}{ Material } & \multicolumn{1}{c|}{ Empresas } & \\
\hline Folders & & \\
\hline Brindes & & \\
\hline Cartazes & & \\
\hline Penduricalhos & & \\
\hline Displays & & \\
\hline Fachada & & \\
\hline Outros & & \\
\hline
\end{tabular}

Materiais de destaque

Oportunidade publicitária

\section{- Concessão de crédito}

Identificar as formas de pagamento (Ex: cheque/cartão) e o prazo (Ex: 30 dias no cheque).

\begin{tabular}{|l|l|l|}
\hline Formas de pagamento & & \\
\hline Prazo/Juros & & \\
\end{tabular}

\section{- $\quad$ Espaço da prateleira (em \%)}

Conforme o que puder ser observado, atribuir porcentagem do espaço da loja ocupado pelos produtos de cada empresa dentro de determinada linha (Atenção: somatório por linha deve ser igual a 100\%).

\begin{tabular}{|c|c|c|c|c|c|}
\hline Fab. Linha & A & B & C & D & $\ldots$ \\
\hline 1 & & & & & \\
\hline 2 & & & & & \\
\hline 3 & & & & & \\
\hline 4 & & & & & \\
\hline 5 & & & & & \\
\hline
\end{tabular}


- Indicadores quantitativos

Identificar o peso contido na embalagem e listar o preço de venda do estabelecimento, o prazo e os juros concedidos pelos fabricantes.

Identificar, se possível percentualmente, quanto cada produto é mais vendido, bem como quanto cada

fabricante vende mais (Atenção: somatório deve ser igual a 100\%). Caso contrário, listar apenas a ordem (Ex: qual é o mais vendido em $1 \%$ lugar, $2^{\circ}, 3^{\circ}$...).

Tentar conseguir informações como o ponto forte e o ponto fraco técnico dos produtos. Caso contrário, obter apenas a impressão do vendedor acerca das melhores marcas em qualidade ou em preço.

\begin{tabular}{|c|c|c|c|c|c|c|c|}
\hline Empresa & Produto & Emb. & Preço & Prazo & Juros & $\begin{array}{c}\% \\
\text { Vendas }\end{array}$ & $\begin{array}{l}\text { Atributos técnicos } \\
\text { Qualidade x preço }\end{array}$ \\
\hline \multirow{6}{*}{-} & A & & & & & & \\
\hline & B & & & & & & \\
\hline & C & & & & & & \\
\hline & D & & & & & & \\
\hline & $\mathrm{E}$ & & & & & & \\
\hline & $\ldots$ & & & & & & \\
\hline \multirow{5}{*}{$N$} & A & & & & & & \\
\hline & B & & & & & & \\
\hline & C & & & & & & \\
\hline & D & & & & & & \\
\hline & & & & & & & \\
\hline
\end{tabular}

